\title{
The BHLH transcription factor DEC1 plays an important role in the epithelial-mesenchymal transition of pancreatic cancer
}

\author{
YUNYAN WU $^{1,2}$, FUYUKI SATO ${ }^{1}$, TOSHIYUKI YAMADA ${ }^{3}$, UJJAL KUMAR BHAWAL ${ }^{4}$, TAKESHI KAWAMOTO ${ }^{5}$, \\ KATSUMI FUJIMOTO ${ }^{5}$, MITSUHIDE NOSHIRO ${ }^{5}$, HIROKO SEINO $^{1}$, SATOKO MOROHASHI $^{1}$, \\ KENICHI HAKAMADA ${ }^{6}$, YOSHIMITSU ABIKO ${ }^{4}$, YUKIO KATO ${ }^{5}$ and HIROSHI KIJIMA ${ }^{1}$ \\ ${ }^{1}$ Department of Pathology and Bioscience, Hirosaki University Graduate School of Medicine, Hirosaki 036-8562, Japan; \\ ${ }^{2}$ Department of Pathology, The First Affiliated Hospital and College of Basic Medical Sciences of China \\ Medical University, Shenyang 110001, P.R. China; ${ }^{3}$ Department of Biochemistry and Genome Biology, \\ Hirosaki University Graduate School of Medicine, Hirosaki 036-8562; ${ }^{4}$ Department of Biochemistry and Molecular \\ Biology Nihon University School of Dentistry at Matsudo, Chiba 271-8587; ${ }^{5}$ Department of Dental and \\ Medical Biochemistry, Hiroshima University Graduate School of Biomedical Science, Hiroshima 734-8553; \\ ${ }^{6}$ Department of Gastrointestinal Surgery, Hirosaki University Graduate School of Medicine, Hirosaki 036-8562, Japan
}

Received February 3, 2012; Accepted April 23, 2012

DOI: $10.3892 /$ ijo.2012.1559

\begin{abstract}
DEC1 (BHLHE40/Stra13/Sharp2) is a basic helixloop-helix (bHLH) transcription factor that is involved in the regulation of apoptosis and cell proliferation and the response to hypoxia. Epithelial-mesenchymal transition (EMT) is an important step leading to invasion and migration of various tumor cells, and TGF- $\beta$ treatment has been shown to induce cancer cells to undergo EMT. However, the significance of DEC1 in TGF- $\beta$-induced EMT remains unknown. We examined the role of DEC1 in EMT of PANC-1 cells, a human pancreatic cancer cell line. As a result, we found that DEC1 was upregulated by TGF- $\beta$ in PANC- 1 cells, and regulated the expression and the levels of nuclear, cytoplasmic or membrane localization of EMT-related factors, including phosphorylated Smad3 (pSmad3), snail, claudin-4 and N-cadherin. In the presence of TGF- $\beta$, DEC1 knockdown by siRNA inhibited morphological changes during EMT processes, while TGF- $\beta$ induced PANC-1 cells to taken on a spindle-shaped morphology. Furthermore, a combination treatment of DEC1 expression with TGF- $\beta$ was closely linked to the migration and invasion of PANC-1 cells. Immunohistochemically, DEC1 and pSmad3 were detected within pancreatic cancer tissues, whereas claudin- 4 expression
\end{abstract}

Correspondence to: Dr Fuyuki Sato, Department of Pathology and Bioscience, Hirosaki University Graduate School of Medicine, 5 Zaifu-cho, Hirosaki 036-8562, Japan

E-mail: fsatodec1dec2@yahoo.co.jp

Abbreviations: DEC1, differentiated embryonic chondrocyte gene 1 ; TGF- $\beta$, transforming growth factor- $\beta$; EMT, epithelialmesenchymal transition; PANC-1, human pancreatic cancer

Key words: differentiated embryonic chondrocyte gene 1, epithelial-mesenchymal transition, transforming growth factor- $\beta$, human pancreatic cancer was weaker in the cancer tissues compared with the adjacent non-cancer pancreatic tissues. These findings suggest that DEC1 plays an important role in the regulation of these EMT-related factors in pancreatic cancer.

\section{Introduction}

Epithelial-mesenchymal transition (EMT) is a dynamic process that occurs during the tumor progression of various cancers. It is characterized by the loss of epithelial factors, including E-cadherin, claudins, and cytokeratins, and the upregulated expression of mesenchymal markers, including N-cadherin, vimentin and fibronectin. Cancer cells that have undergone EMT are thought to acquire a fibroblast-like motile and an invasive phenotype $(1,2)$.

Transforming growth factor (TGF)- $\beta$ one of the most potent inducers of EMT, induces spindle-shaped cell morphology, inhibits cell proliferation, and promotes tumor cell motility and invasion (2-4). TGF- $\beta$ binds to two different serine/threonine kinase receptors; type I (TGF- $\beta$ RI) and type II receptors (TGF- $\beta$ RII). The formation of hetero-dimers of TGF- $\beta$ RI and TGF- $\beta$ RII leads to the activation of the signaling pathways mediated by TGF- $\beta$ (5). Human pancreatic cancer (PANC-1) cells express both TGF- $\beta$ RI and TGF- $\beta$ RII, whereas MIA $\mathrm{PaCa}-2$ pancreatic cancer cells do not express either of them (6). Smads are key intracellular mediators of the transcriptional responses to TGF- $\beta$, and Smad4 mutations are known to be present in more than $50 \%$ of pancreatic cancer cases $(7,8)$. In addition, the activation of other Smads plays important roles in the tumor progression of pancreatic cancer. The phosphorylation of Smad2 and Smad3 causes them to translocate from the cytoplasm to the nucleus and associate with Smad4. In the nucleus, the activated Smad complex binds to target gene promoters and regulates the transcriptional responses to TGF- $\beta(5,9,10)$.

There are several EMT inducing transcription factors, such as snail, slug, twist and ZEB1 (11-14). Since there were some 
reports on the roles of snail in PANC-1, we selected snail as a marker of positive control during EMT. Snail is expressed in various tumor cells and regulates the expression of E-cadherin, claudins, and some mesenchymal markers, which are involved in tumor invasion, metastasis, and cell motility $(1,15,16)$. Furthermore, TGF- $\beta$ directly activates snail transcription through the Smad3 phosphorylation (17).

We have shown that DEC1 (BHLHE40/Stra13/Sharp2) is involved in the regulation of apoptosis and the cell cycle in human breast and oral cancer cells (18-20). DEC1 is also highly expressed in various tumors (20-24). However, the role of DEC1 in EMT is still unknown. In this study, we focused on the role of DEC1 in EMT of pancreatic cancer cells during TGF- $\beta$ treatment and demonstrated that DEC1 plays important roles in EMT of pancreatic cancer cells.

\section{Materials and methods}

Cell culture and treatment. Human pancreatic cancer PANC-1 and MIA PaCa-2 cells were cultured as described previously $(25,26)$. These cells were incubated with recombinant human TGF- $\beta$ (R\&D Systems, Minneapolis, MN, USA) or A-83-01 (Takara, Shiga, Japan) at various concentrations and periods.

Knockdown of DEC1 by RNA interference. Short interference RNA (siRNA) against DEC1 was synthesized by Qiagen (Hilden, Germany). The sequences of the sense and anti-sense DEC1 siRNA and the negative control (scrambled) siRNA, and the siRNA transfection were performed as described previously (18).

DEC1 overexpression. DEC1 overexpression was induced using pcDNA vector as described previously (19). After transfection, the cells were incubated for $24 \mathrm{~h}$ and subjected to the invasion assay.

Western blotting. Cells were lysed using M-PER lysis buffer (Thermo Scientific, Rockford, IL, USA) and their protein concentration was determined using the bicinchoninic acid (BCA) assay. Their lysates were subjected to SDS-PAGE and detected the protein expression as described previously $(18,19)$.

Antibodies. The membranes for western blotting were incubated with antibodies specific to DEC1 (1:10,000; Novus Biologicals Inc., Littleton, CO, USA), Smad3 (1:1,000; Epitomics Inc., Burlingame, CA, USA), pSmad3 (1:6,000; Epitomics), phospho extracellular signal-related kinases (p-ERK) 1/2 (1:1,000; Epitomics), pSmad2 (1:5,000; Invitrogen, Carlsbad, CA, USA), slug (1:3,000; Cell Signaling Technology Inc.), snail (1:3,000; Cell Signaling Technology Inc., Danvers, MA, USA), ERK1/2 (1:30,000; Cell Signaling Technology Inc.), $\alpha$-smooth muscle actin ( $\alpha$-SMA) (1:20,000; Sigma Chemical Co., St. Louis, MO, USA), vimentin (1:10,000; Epitomics), N-cadherin (1:10,000; ECM Biosciences, Versailles, KY, USA), E-cadherin (1:1000; Takara), claudin-1 (1:10,000; Invitrogen), claudin-4 (1:20,000; Invitrogen), claudin-7 (1:1,000; Invitrogen), and actin (1:30,000; Sigma), followed by horseradish peroxidase-conjugated secondary antibody (Immuno-Biological Laboratories, Fujioka, Japan). Can Get Signal immunoreaction enhancer solution (Toyobo Co. Ltd., Osaka, Japan) or Immunoshot immuno- reaction enhancer solution (Cosmobio Co. Ltd., Tokyo, Japan) was used to dilute the primary antibody.

Real-time polymerase chain reaction $(P C R)$. We prepared three independent RNA samples $(\mathrm{n}=3)$. Total-RNA was isolated and first-strand cDNA was synthesized as described previously (19). The real-time PCR was performed using SYBR-Green Master Mix (Life Technologies, Carlsbad, CA, USA). The sequences of the primers and the sizes of products are shown in Table I.

Immunofluorescent staining. Immunofluorescent staining was performed as described previously (18). The permeabilized cells were incubated with anti-DEC1 (1:300), pSmad3 (1:300), snail (1:300), N-cadherin (1:300), E-cadherin (1:300), claudin-1 (1:300), claudin-4 (1:300), or claudin-7 (1:300) antibodies at $4^{\circ} \mathrm{C}$ overnight. The cells were then incubated for $1 \mathrm{~h}$ with goat antirabbit IgG antibody conjugated to Alexa 488 dye (Molecular Probes Inc., Tokyo, Japan), while nuclear staining was performed using 4',6-diamidino-2-phenylindole (DAPI). These cells were visualized using confocal laser scanning microscopy LSM 710 (Zeiss, Wetzlar, Germany).

Cell stain was carried out using the CnT-ST-100 stain kit (CellnTEC Advanced Cell Systems AG, Bern, Switzerland), in accordance with the manufacturer's instructions.

Invasion assay and migration assay. The invasion assay was performed using a BD BioCoat Matrigel invasion chamber kit (Becton Dickinson, Franklin Lakes, NJ, USA). PANC-1 cells were separated using cell dissociation solution (Sigma) and then $\left(5 \times 10^{4}\right.$ cells $\left./ 600 \mu \mathrm{l}\right)$ were added to the top chamber of a cell culture insert in a 24-well companion plate. After overnight incubation, the cells that had invaded the lower surface of the membrane were fixed with methanol and subjected to Giemsa staining. The number of cells that had migrated was quantified by counting them in ten random distinct fields using a light microscope.

For the migration assay, PANC-1 cells were seeded in a 4-chamber slide glass, and an artificial 'wound' was carefully created at $0 \mathrm{~h}$ by scratching the confluent cell monolayer with the tip of a P-200 pipette. Microphotographs were taken at 0, 24 and $48 \mathrm{~h}$.

Human pancreatic tissues. We examined immunohistochemical analyses of surgically resected pancreatic cancers $(n=17)$, which have been filed in Hirosaki University Hospital, Japan (Table II). All of the 17 cases examined were invasive ductal carcinoma of pancreas. Histological specimens were retrieved from the archives of our hospital according to the guidelines produced by the Japanese Society of Pathology.

Immunohistochemistry. Immunohistochemistry was performed as described previously (27). The sections were incubated overnight at $4^{\circ} \mathrm{C}$ with anti-DEC1 (1:100),pSmad3 (1:200), or claudin-4 (1:400) antibodies diluted in Can Get Signal Immunostain Solution (Toyobo Co.). Finally, the sections were counterstained with Mayer's hematoxylin.

\section{Results}

DECl expression was induced by TGF- $\beta$ in PANC-1 cells. TGF- $\beta$ treatment induced Smad3 phosphorylation, and upregu- 
Table I. Sequences of the primer sets and the product sizes of real-time PCR.

\begin{tabular}{|c|c|c|}
\hline Gene & Product size (bp) & Primer sequences \\
\hline$D E C 1$ & 76 & $\begin{array}{l}\text { F: 5'-GAAAGGATCGGCGCAATTAA-3' } \\
\text { R: 5'-CATCATCCGAAAGCTGCATC-3' }\end{array}$ \\
\hline Snail & 73 & $\begin{array}{l}\text { F: 5'-CTTCAACTGCAAATACTGCAACAAG-3' } \\
\text { R: 5'-GCGTGTGGCTTCGGATGT-3' }\end{array}$ \\
\hline E-cadherin & 75 & $\begin{array}{l}\text { F: 5'-ACAGTCACTGACACCAACGATAATC-3' } \\
\text { R: 5'-ACTGCTGCTTGGCCTCAAA-3' }\end{array}$ \\
\hline Claudin-4 & 64 & $\begin{array}{l}\text { F: 5'-TGGGAGGGCCTATGGATGA-3' } \\
\text { R: 5'-TCGTACACCTTGCACTGCATCT-3' }\end{array}$ \\
\hline$N$-cadherin & 77 & $\begin{array}{l}\text { F: 5'-TGATCGAGAAAAAGTGCAACAGTAT-3' } \\
\text { R: 5'-GGCTGTGTTTGAAAGGCCATA-3' }\end{array}$ \\
\hline$T G F-\beta R I$ & 105 & $\begin{array}{l}\text { F:5'-CTGAAGTTCTCGATGATTCCATAAATAT-3 } \\
\text { R: 5'-GAACATCGTCGAGCAATTTCC-3' }\end{array}$ \\
\hline $18 S$ rRNA & 150 & $\begin{array}{l}\text { F: 5'-GTAACCCGTTGAACCCCATT-3' } \\
\text { R: 5'-CCATCCAATCGGTAGTAGCG-3' }\end{array}$ \\
\hline
\end{tabular}

$\mathrm{F}$, forward primer; $\mathrm{R}$, reverse primer.

Table II. Immunohistochemical expression of DEC1, pSmad3, and claudin-4 proteins in human pancreatic cancer tissues.

\begin{tabular}{|c|c|c|c|c|c|c|c|c|}
\hline \multirow[b]{2}{*}{$\mathrm{C}$} & \multirow[b]{2}{*}{$\mathrm{A} / \mathrm{S}$} & \multirow[b]{2}{*}{$\mathrm{D}$} & \multicolumn{2}{|c|}{ DEC1 } & \multicolumn{2}{|c|}{ pSmad3 } & \multicolumn{2}{|c|}{ claudin-4 } \\
\hline & & & $\mathrm{T}$ & $\mathrm{N}$ & $\mathrm{T}$ & $\mathrm{N}$ & $\mathrm{T}$ & $\mathrm{N}$ \\
\hline 1 & $66 / F$ & Moderately & Strong & Weak & Strong & Weak & Weak & Strong \\
\hline 2 & $62 / \mathrm{M}$ & Moderately & Strong & Weak & Strong & Weak & Strong & Weak \\
\hline 3 & $66 / F$ & Moderately & Strong & Weak & Strong & Weak & Weak & Strong \\
\hline 4 & $66 / \mathrm{M}$ & Moderately & Strong & Weak & Strong & Weak & Weak & Strong \\
\hline 5 & $67 / F$ & Moderately & Strong & Weak & Strong & Weak & Weak & Strong \\
\hline 6 & $62 / F$ & Moderately & Strong & Weak & Strong & Weak & Weak & Strong \\
\hline 7 & $75 / \mathrm{M}$ & Moderately & Strong & Weak & Strong & Strong & Weak & Strong \\
\hline 8 & $58 / \mathrm{M}$ & Moderately & Strong & Strong & Strong & Weak & Weak & Strong \\
\hline 9 & $65 / \mathrm{M}$ & Moderately & Strong & Weak & Strong & Weak & Weak & Strong \\
\hline 10 & $72 / \mathrm{F}$ & Well & Strong & Weak & Strong & Weak & Strong & Weak \\
\hline 11 & $67 / \mathrm{M}$ & Poorly & Strong & Weak & Strong & Strong & Weak & Strong \\
\hline 12 & $71 / \mathrm{F}$ & Well & Strong & Weak & Strong & Weak & Weak & Weak \\
\hline 13 & $74 / \mathrm{M}$ & Moderately & Strong & Strong & Strong & Weak & Weak & Strong \\
\hline 14 & $72 / \mathrm{M}$ & Poorly & Strong & Weak & Strong & Weak & Strong & Weak \\
\hline 15 & $55 / \mathrm{M}$ & Moderately & Strong & Weak & Strong & Weak & Weak & Weak \\
\hline 16 & $61 / \mathrm{F}$ & Moderately & Strong & Strong & Strong & Strong & Weak & Strong \\
\hline 17 & $50 / \mathrm{F}$ & Moderately & Strong & Weak & Strong & Weak & Strong & Weak \\
\hline
\end{tabular}

C, cases; A/S, age (yr)/sex; D, differentiation of pancreatic cancer; T, tumor cells; N, Adjacent non-tumor cells.

lated the expression of DEC1, snail, $\alpha$-SMA, vimentin and $\mathrm{N}$-cadherin, whereas it downregulated E-cadherin, claudin-1 and claudin-4 in PANC-1 cells (Fig. 1A and B). The highest level of DEC1 expression was observed in the cells treated with $2 \mathrm{ng} / \mathrm{ml}$ of TGF- $\beta$ for $24 \mathrm{~h}$. TGF- $\beta$ had little effect on the Smad2 phosphorylation and the expression of Smad3, slug and claudin-7 in PANC-1 cells. On the other hand, no apparent effects were observed on the expression of the aforementioned molecules after TGF- $\beta$ treatment in MIA PaCa- 2 cells. Next, we investigated the endogenous mRNA expression of these proteins in PANC-1 cells treated with TGF- $\beta$. The expression of DEC1, snail and $\mathrm{N}$-cadherin was upregulated by TGF- $\beta$, whereas the expression of E-cadherin and claudin-4 was downregulated (Fig. 1C). A-83-01-an inhibitor of the TGF- $\beta$ signaling pathway prevents $S \operatorname{mad} 2 / 3$ phosphorylation. We therefore investigated whether A-83-01 affects the Smad3 phosphorylation and 

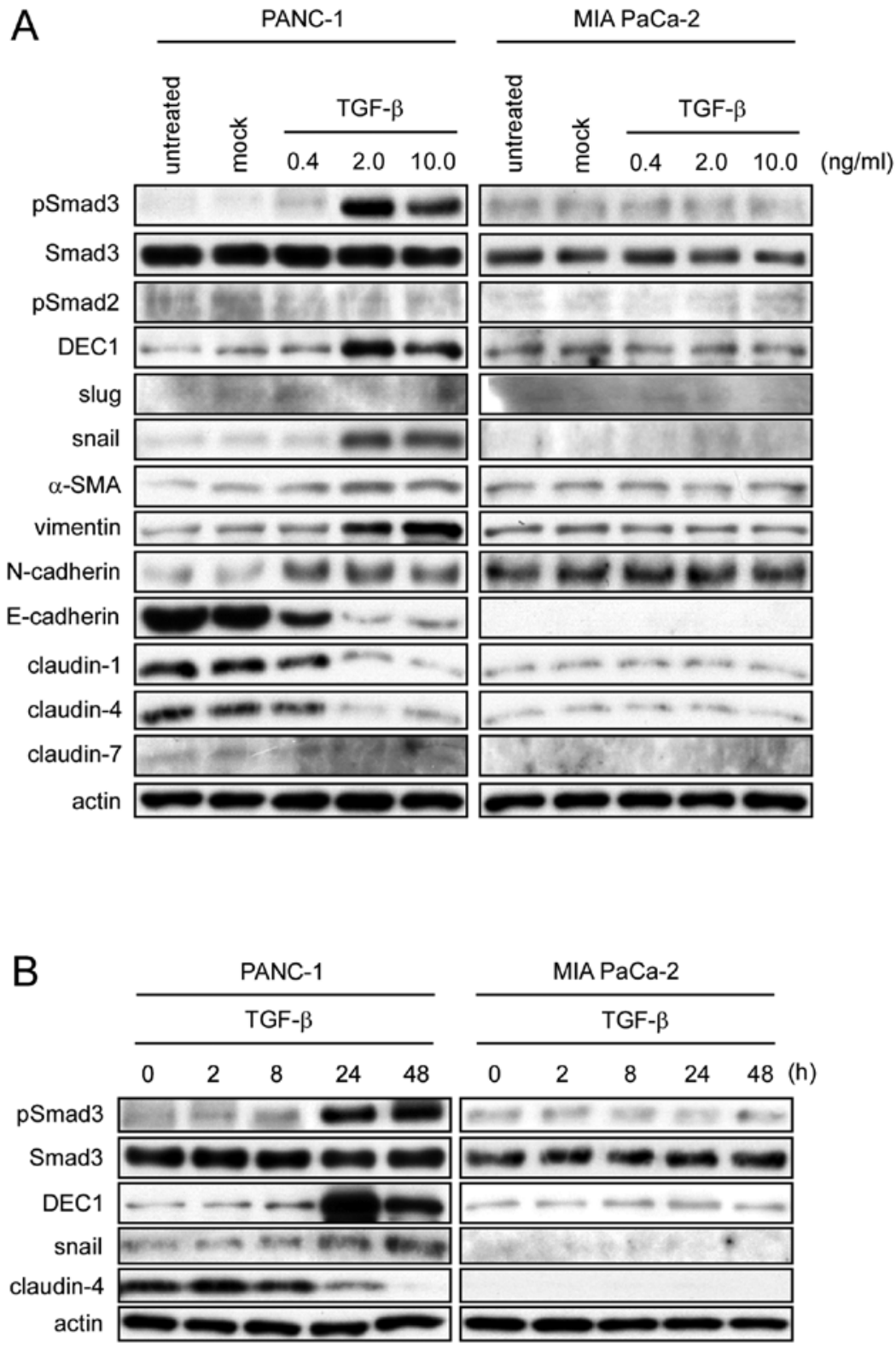

Figure 1. DEC1 expression is upregulated by TGF- $\beta$ in human pancreatic cancer PANC-1 cells. (A) PANC-1 and MIA PaCa-2 cells were treated with various concentrations of TGF- $\beta$ for $24 \mathrm{~h}$. The control cells (mock) were treated with TGF- $\beta$-diluted buffer. These cells were then lysed and the lysates were subjected to western blot analyses of pSmad3, Smad3, pSmad2, DEC1, slug, snail, $\alpha$-SMA, vimentin, N-cadherin, E-cadherin, claudin-1, claudin-4, claudin-7 and actin . One representative of at least three independent experiments with similar results is shown. (B) PANC-1 and MIA PaCa-2 cells were treated with TGF- $\beta$ $(2 \mathrm{ng} / \mathrm{ml})$ for various periods. The cells were lysed, and the lysates were subjected to western blot analyses of pSmad3, Smad3, DEC1, snail, claudin-4 and actin. One representative of at least three independent experiments with similar results is shown.

DEC1 expression induced by TGF- $\beta$ in PANC-1 cells. A-83-01 suppressed the Smad3 phosphorylation, and the expression of DEC1 and snail. On the other hand, claudin-4 expression was upregulated by A-83-01 (Fig. 1D).

DEC1 knockdown suppressed EMT induced by TGF- $\beta$. The cells that were transfected with the control siRNA showed a spindle-shaped morphology after $24 \mathrm{~h}$ treatment with TGF- $\beta$, while the cells transfected with DEC1 siRNA displayed no morphological changes after the same treatment (Fig. 2A). As shown in Fig. 2B, in the absence of TGF- $\beta$, DEC1 siRNA upregulated the expression of claudin-4, claudin-7 and E-cadherin, and downregulated the expres- sion of N-cadherin, whereas it had little effect on the Smad3 phosphorylation, and the expression of snail and claudin-1. In the presence of TGF- $\beta$, DEC1 siRNA decreased the Smad3 phosphorylation, and the expression of snail and $\mathrm{N}$-cadherin, whereas it upregulated the expression of claudin-1, claudin-4, claudin-7, and E-cadherin. In the presence or absence of TGF- $\beta$, DEC1 siRNA had little effect on the ERK1/2 phosphorylation, and the expression of total-ERK1/2, $\alpha$-SMA and vimentin. Another DEC1 siRNA oligonucleotide yielded similar results (data not shown). In order to examine whether DEC1 regulates EMT-related factors at the transcriptional level, we performed real-time PCR analysis. The altered mRNA expression patterns of snail, E-cadherin, claudin-4 
C
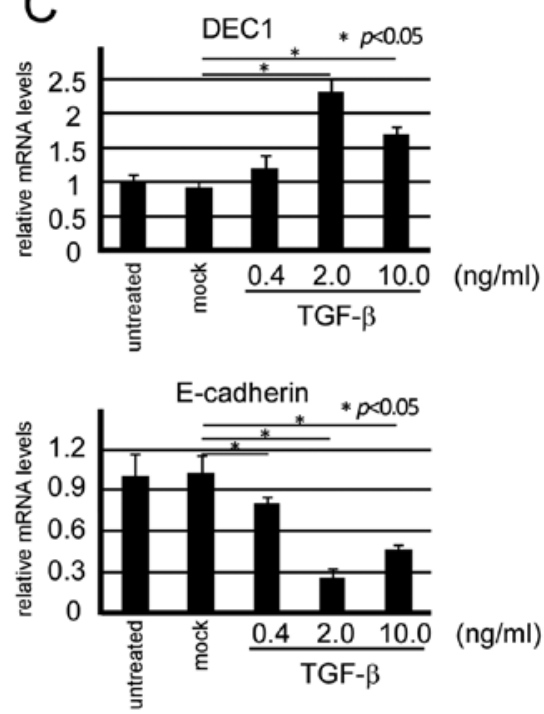

( $\mathrm{ng} / \mathrm{ml})$

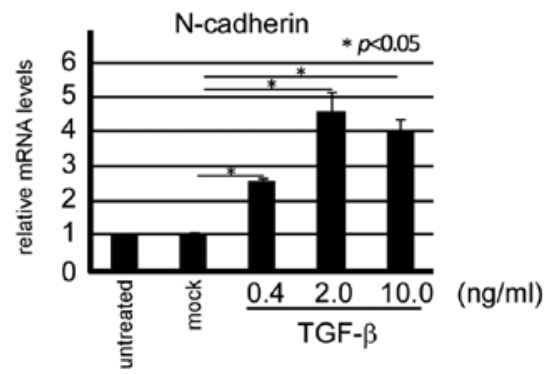

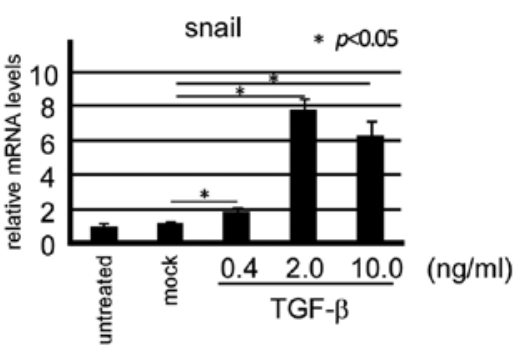

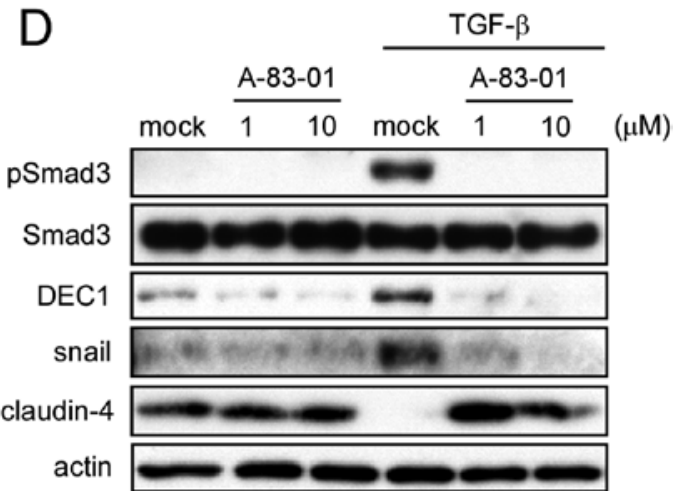

Figure 1. Continued. (C) PANC-1 cells were treated as above, and total-RNA was prepared and subjected to real-time PCR of DEC1, snail, E-cadherin, claudin-4 and N-cadherin. Each value represents the mean \pm SE (bars) of three independent experiments *p<0.05, according to the t-test. (D) PANC-1 cells were treated with the TGF- $\beta$ inhibitor A-83-01 (1 or $10 \mu \mathrm{M})$ for 90 min before being treated with or without TGF- $\beta$ ( 2 ng/ml) for $24 \mathrm{~h}$, and the lysates were subjected to western blot analyses of pSmad3, Smad3, DEC1, snail, claudin-4 and actin. One representative of at least two independent experiments with similar results is shown.

and $\mathrm{N}$-cadherin were compatible with the above protein results (Fig. 2C). In the presence of TGF- $\beta$, DEC1 siRNA also significantly decreased the expression of TGF- $\beta$ RI, although DEC1 siRNA without TGF- $\beta$ slightly decreased the expression of TGF- $\beta$ RI. DEC1 siRNA regardless of TGF- $\beta$ had little effect on the expression of TGF- $\beta$ RII (data not shown).

Effects of DEC1 knockdown on the amounts of nuclear/cytoplasmic EMT-related factors. As shown in Fig. 2D, DEC1 siRNA without TGF- $\beta$ decreased the amount of N-cadherin in the cell membrane, while it increased the cell membrane levels of E-cadherin, claudin-4 and claudin-7. On the other hand, DEC1 siRNA without TGF- $\beta$ had little effect on the amounts of nuclear/cytoplasmic pSmad3, snail and claudin-1. In the presence of TGF- $\beta$, control siRNA increased the levels of pSmad 3 and snail in the nucleus compared with the absence of TGF- $\beta$, and slightly increased the level of N-cadherin in the cell membrane, whereas it decreased the amounts of E-cadherin and claudin-1 in the cell membrane, and decreased the amount of claudin-4 in the cytoplasm. However, it had little effect on the amount of claudin-7 in the cytoplasm or membrane. In the presence of TGF- $\beta$, DEC1 siRNA decreased the levels of pSmad3 and snail in the nucleus compared with control siRNA, and it also decreased the amount of $\mathrm{N}$-cadherin in the cell membrane.
On the other hand, a combination treatment of DEC1 siRNA with TGF- $\beta$ significantly increased the levels of E-cadherin, claudin-1 and claudin-4 in the cell membrane compared with control siRNA. A combination treatment of DEC1 siRNA with TGF- $\beta$ also slightly increased the amount of claudin-7 in the cell membrane. These findings demonstrated that DEC1 has inducible effects on EMT in PANC-1 cells during TGF- $\beta$ treatment, which involved alterations in the cellular amounts of EMT-related factors.

In the presence of TGF- $\beta, D E C 1$ expression was closely involved in the migration and invasion. We examined whether DEC1 expression was involved in the migration and invasion of PANC- 1 cells. In the presence of TGF- $\beta$, DEC 1 siRNA delayed cell migration for $24-48 \mathrm{~h}$ in comparison with those transfected with the control siRNA (Fig. 3). We performed an invasion assay in which we transiently transfected the cells with a DEC1 expressing plasmid. As a result, the number of invasive PANC-1 cells with a spindle-shaped morphology was increased in the presence of TGF- $\beta$ (Fig. 4). The invasion assay also demonstrated that there were significantly more invasive spindle-shaped cells among the cells transfected with DEC1 than among those transfected with the control pcDNA vector. 
A

$(-)$

TGF- $\beta$

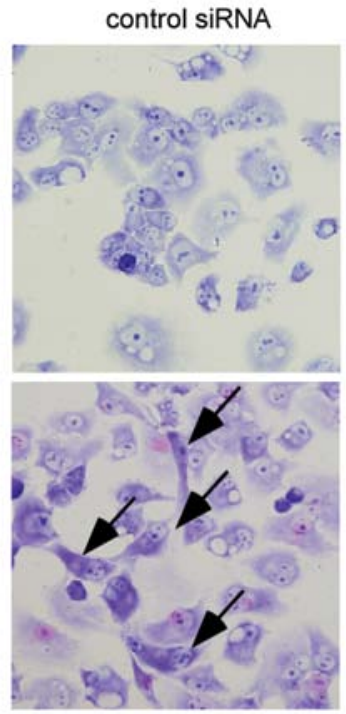

DEC1 SIRNA

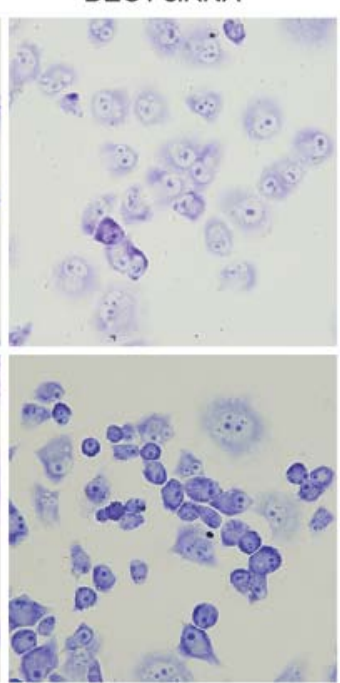

DEC1, pSmad3 and claudin-4 protein expression in human pancreatic cancer tissues and the adjacent non-cancerous pancreatic tissues. We examined the immunohistochemical expression of DEC1, pSmad3 and claudin-4 in human pancreatic cancer tissues. Photographs of DEC1, pSmad3 and claudin-4 expression in representative cases are shown in Fig. 5. Significant DEC1 immunoreactivity was detected in the cancer tissues (100\%, 17/17 cases) compared with the adjacent non-cancerous pancreatic tissues, and it was predominantly located within the cytoplasm of the cancer cells, although very weak DEC1 immunoreactivity was found in the non-cancerous pancreatic ductal cells of all cases. DEC1 immunoreactivity was detected in parts of the adjacent non-cancerous tissues (17\%, 3/17 cases).

It is often difficult to distinguish between spindle-shaped cells of the cancer invasive front and fibroblasts in stroma. We distinguish them by dyskaryosis and size. Firstly, dyskaryosis was shown in spindle-shaped cells, whereas it was not shown

B
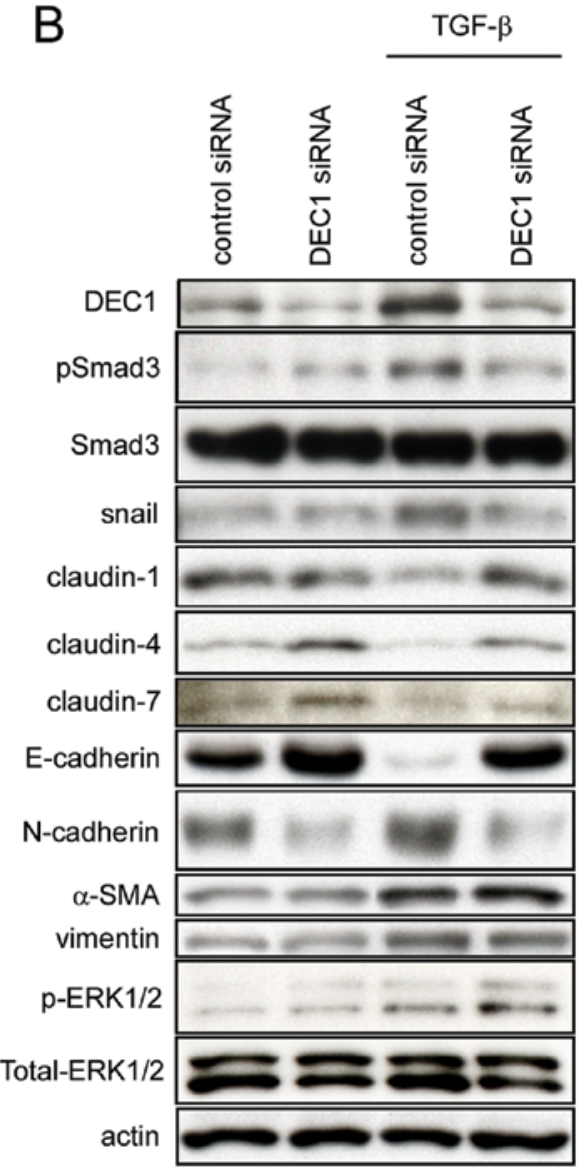

C
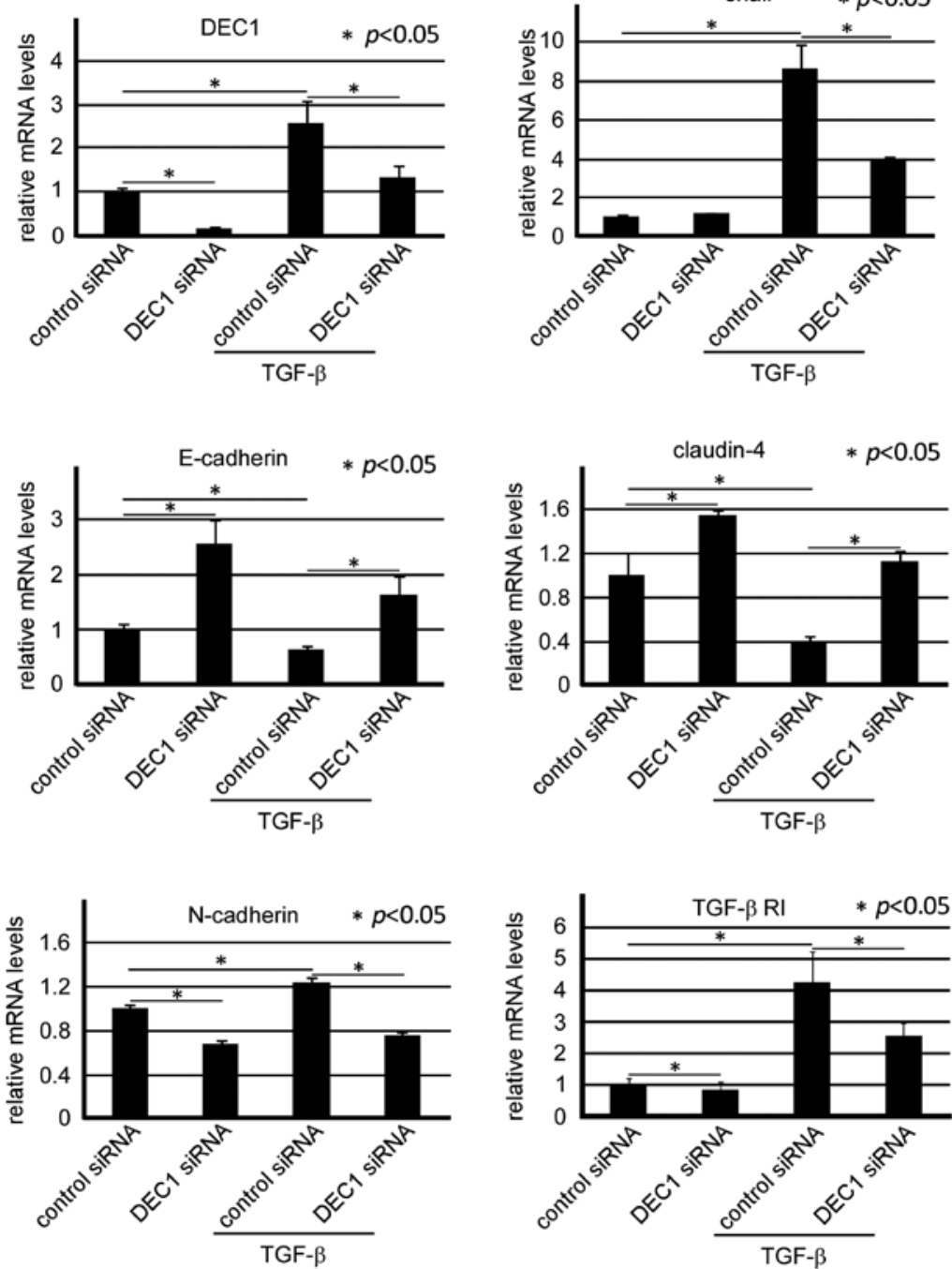
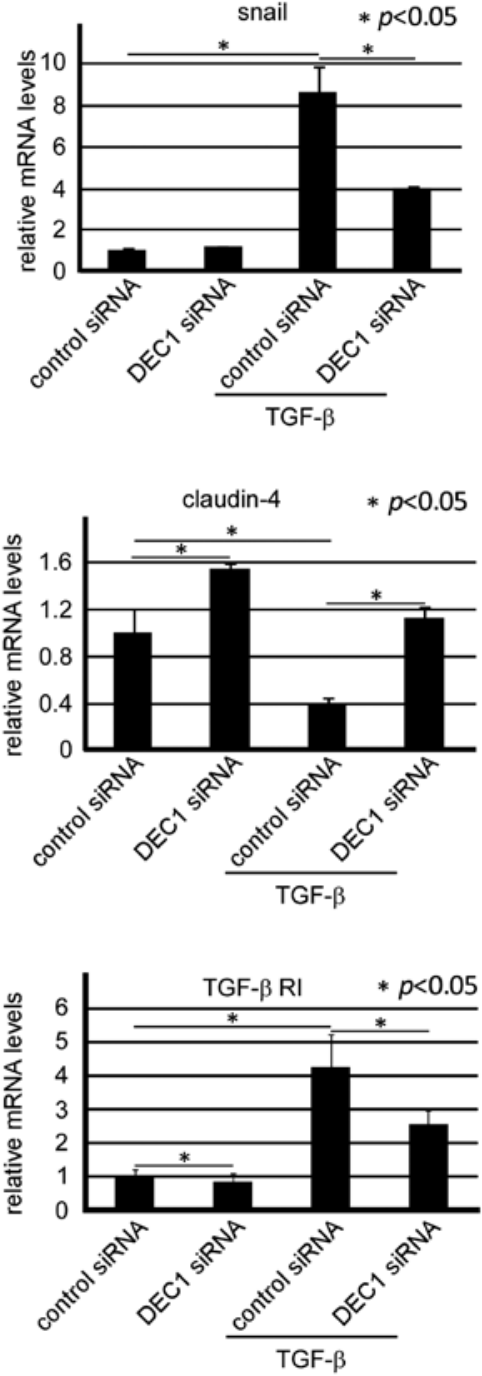

Figure 2. DEC1 knockdown inhibits TGF- $\beta$-induced EMT in PANC-1 cells. (A) PANC-1 cells were transfected with control siRNA or siRNA against DEC1. At $24 \mathrm{~h}$ post-transfection, the cells were treated with or without TGF- $\beta(2 \mathrm{ng} / \mathrm{ml})$ and incubated for $24 \mathrm{~h}$. The cells were then fixed, stained and observed in bright field. The black arrows show spindle-shaped cancer cells. One representative of at least two independent experiments with similar results is shown. (B) PANC-1 cells were treated with control siRNA or DEC1 siRNA in the presence or absence of TGF- $\beta$ ( $2 \mathrm{ng} / \mathrm{ml})$ for $24 \mathrm{~h}$, and the lysates were subjected to western blot analyses of DEC1, pSmad3, Smad3, snail, claudin-1, claudin-4, claudin-7, E-cadherin, N-cadherin, $\alpha$-SMA, vimentin, pERK1/2, total-ERK1/2 and actin. One representative of at least three independent experiments with similar results is shown. (C) PANC-1 cells were treated as above, and total-RNA was prepared and subjected to real-time PCR of DEC1, snail, E-cadherin, claudin-4, N-cadherin, and TGF- $\beta R I$. Each value represents the mean \pm SE (bars) of three independent experiments ${ }^{*} \mathrm{p}<0.05$, according to the $\mathrm{t}$-test. 


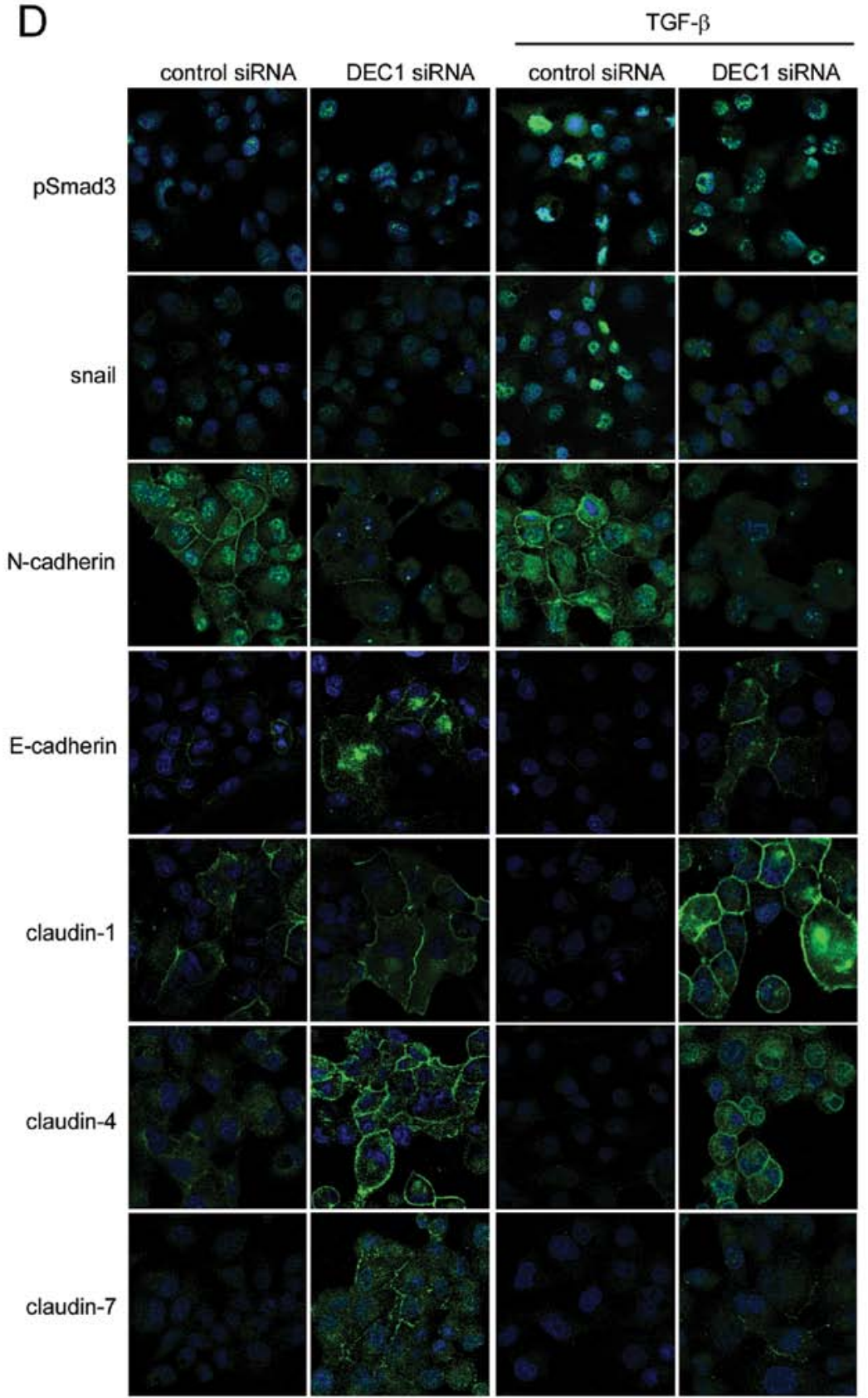

Figure 2. Continued. (D) PANC-1 cells were transfected with control siRNA or siRNA against DEC1. At $24 \mathrm{~h}$ post-transfection, the cells were treated with or without TGF- $\beta(2 \mathrm{ng} / \mathrm{ml})$ and incubated for $24 \mathrm{~h}$. The cells were then fixed, incubated with anti-pSmad3, snail, N-cadherin, E-cadherin, claudin-1, claudin-4, or claudin-7 antibodies, and visualized using Alexa488-conjugated secondary antibody (green). The cells were also counterstained with DAPI (blue) in order to detect their nucleus. A merged image that is representative of at least two independent experiments with similar results is shown.

in fibroblasts in stroma. Secondary, the sizes of spindle-shaped cells were larger than fibroblasts. The spindle-shaped cells of the cancer invasive front showed strong DEC1 immunoreactivity similar to that seen in the other cancer regions (case 9 , right panel). Marked claudin-4 immunoreactivity was detected in the membrane and/or cytoplasm of non-cancerous pancreatic ductal cells, whereas that in the cancer cells was weak, except for 4 cases in which strong claudin- 4 expression was detected in cancer cells. Significant pSmad3 expression was found in the nucleus of spindle-shaped cancer cells, whereas it was detected in non-cancerous ductal cells in 3 cases. The changes in the immunohistochemical expression of DEC1, pSmad3, and claudin-4 were found to be independent of the cancer grade and the patient's age and gender.

\section{Discussion}

DEC1 is expressed in various tumors and regulates the responses to hypoxia, apoptosis and the cell cycle $(19,20,23,24,28)$. Recent studies have shown that the expression of DEC1 is related to apoptosis resistance in pancreatic cancer cells (29). However, the significance of DEC1 in pancreatic cancer is poorly understood. In the present study, we showed that DEC1 was upregulated by TGF- $\beta$ in PANC-1 cells. DEC1 expression was highest in the 


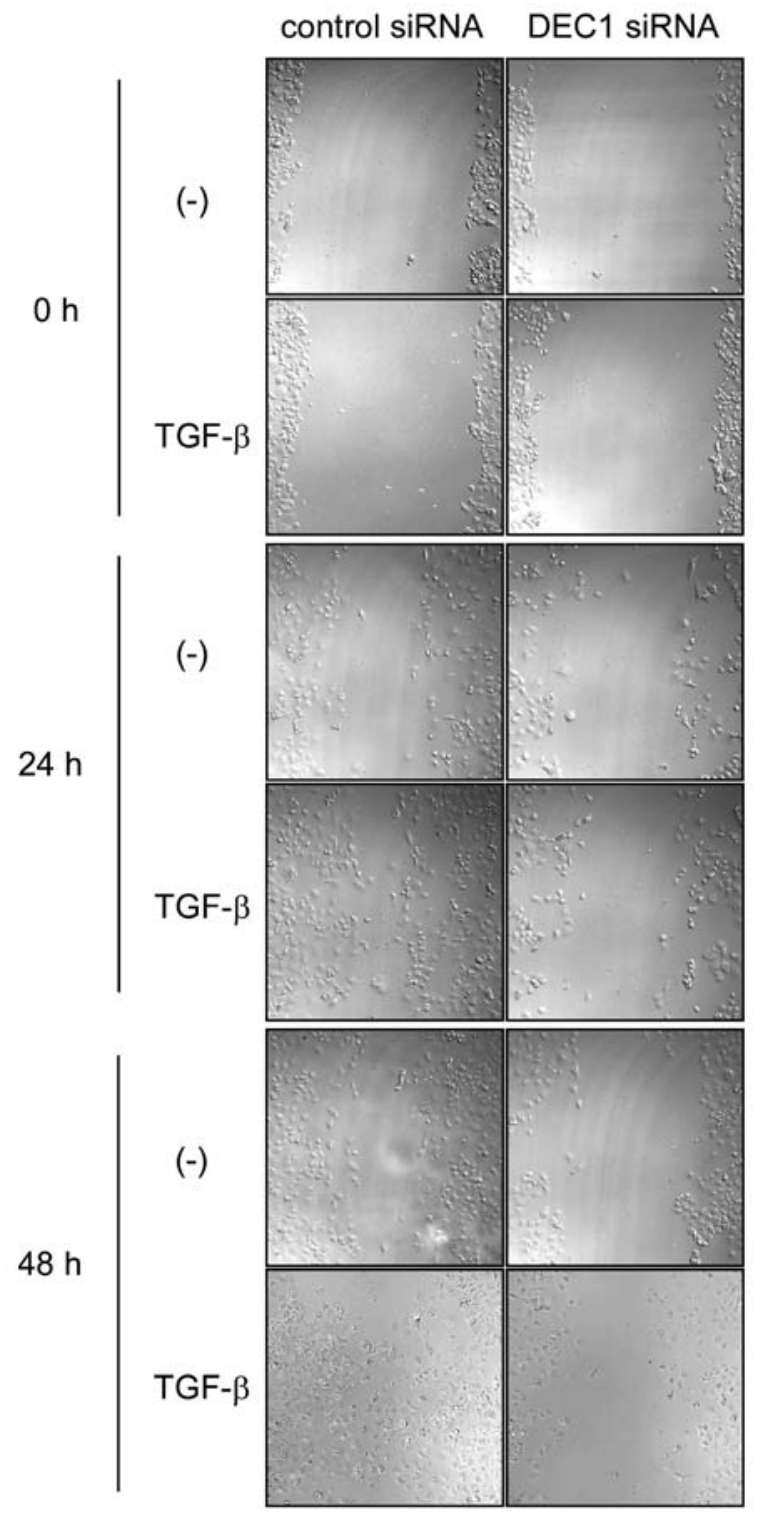

Figure 3. In the presence of TGF- $\beta$, DEC1 siRNA decreased the migration of PANC-1 cells. PANC-1 cells were transfected with control siRNA or siRNA against DEC1. After $24 \mathrm{~h}$ transfection, a wound was made with a pipette tip and photographs of the wounded area were taken periodically.

cells cultured in the presence of TGF- $\beta$ for $24 \mathrm{~h}$, whereas snail expression was highest in the cells cultured in the presence of TGF- $\beta$ for $48 \mathrm{~h}$. PANC- 1 cells showed the highest level of Smad3 phosphorylation when cultured in the presence of TGF- $\beta$ for 24-48 h, which also induced a spindle-shaped morphology and enhanced migration and invasiveness. These findings indicate that EMT of PANC-1 is induced by $24 \mathrm{~h}$ TGF- $\beta$ treatment and that TGF- $\beta$-induced DEC1 expression is closely related to EMT phenomena. Previous studies have reported that TGF- $\beta$ affects circadian phase shifts in rat fibroblasts, as well as the immediateearly induction of DEC1, and Smad binding sites (SBE) were presented in the DEC1 promoter (30). The differences in DEC1 induction time between the previous report and our present study are probably related to cell type. It was reported that TGF- $\beta$ increased the protein expression of Smad4 in PANC-1 cells (31). We performed a chip assay whether Smad3 or Smad4 bound to the DEC1 promoter in PANC-1 cells, and found that in
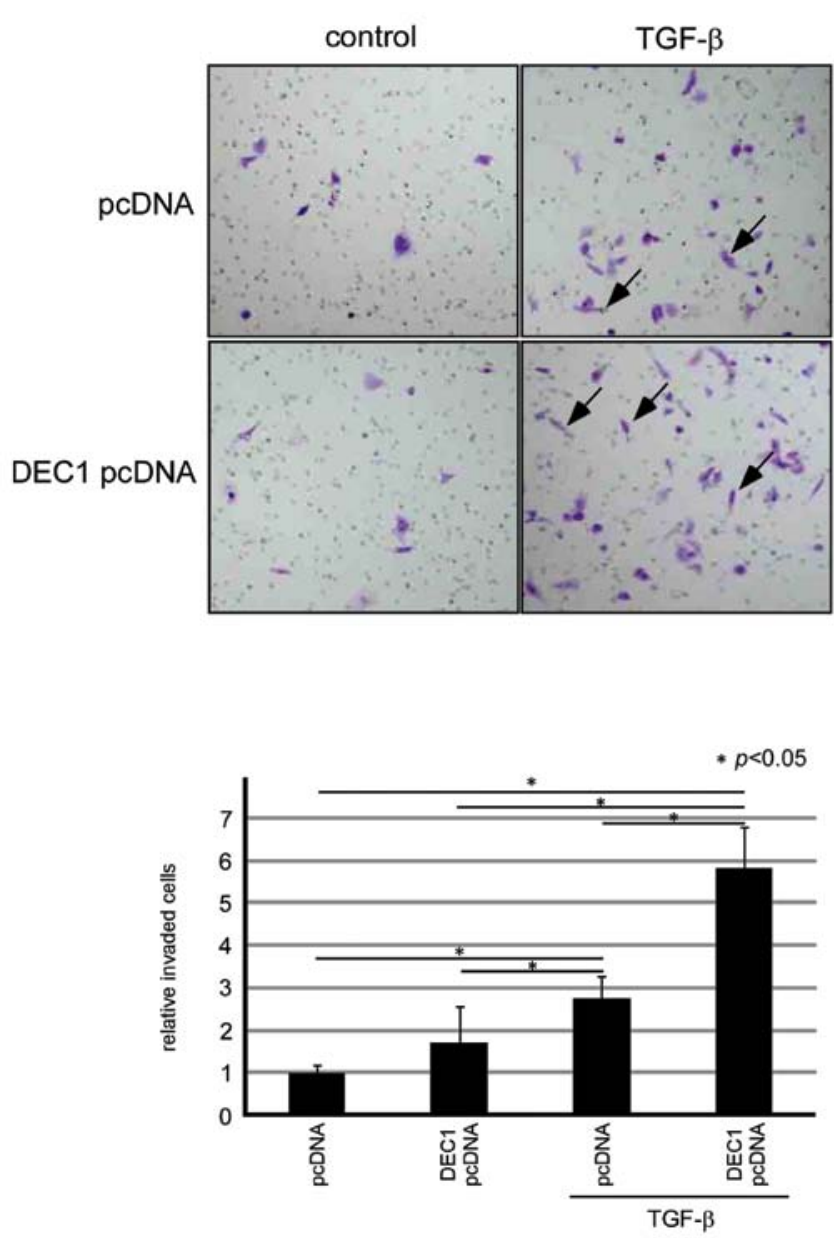

Figure 4. DEC1 overexpression increased the invasion induced by TGF- $\beta$ in PANC-1 cells. PANC-1 cells were transfected with pcDNA or DEC1 pcDNA. At $24 \mathrm{~h}$ post-transfection, the cells were treated with or without TGF- $\beta$ ( $2 \mathrm{ng}$ / $\mathrm{ml}$ ) for $24 \mathrm{~h}$ and $5 \times 10^{4}$ cells each were seeded in the invasion chamber. At $24 \mathrm{~h}$ after cell seeding, the chambers were stained and the numbers of invasive cells was counted. The top panel shows a representative photograph. The black arrows show spindle-shaped cancer cells. The bottom panel shows the quantitative data. Each value represents the mean \pm SE (bars) of three independent experiments ${ }^{*} \mathrm{p}<0.05$, according to the t-test.

the presence of TGF- $\beta, \operatorname{Smad} 3$ or Smad4 bound to the SBE in the DEC1 promoter (data not shown). Thus, we thought, at least, Smad3 or Smad4 might have activities for binding to the DEC1 promoter in PANC-1 cells.

We demonstrated that a combination treatment of DEC1 siRNA with TGF- $\beta$ downregulated the Smad 3 phosphorylation, and the expression of TGF- $\beta$ RI and snail, and it also decreased the amounts of pSmad 3 and snail in the nucleus. These findings suggest that DEC1 is an upstream factor of these genes. It has been reported that DEC1 upregulates and downregulates target genes by binding to sp1 and E-box sites, respectively $(21,32,33)$. The promoter region of TGF- $\beta$ RI contains sp1 sites (34). Therefore, we speculate that DEC1 binds to sp1 sites of the TGF- $\beta$ RI promoter and regulates EMT-related factors through pSmad3/snail signaling. TGF- $\beta$ also affects the ERK1/2 phosphorylation independent of Smad pathway (35). However, DEC1 siRNA regardless of TGF- $\beta$ had little effect on the ERK1/2 phosphorylation. These results suggest that DEC1 specifically regulates the pSmad3/snail pathway induced by TGF- $\beta$. In MIA 


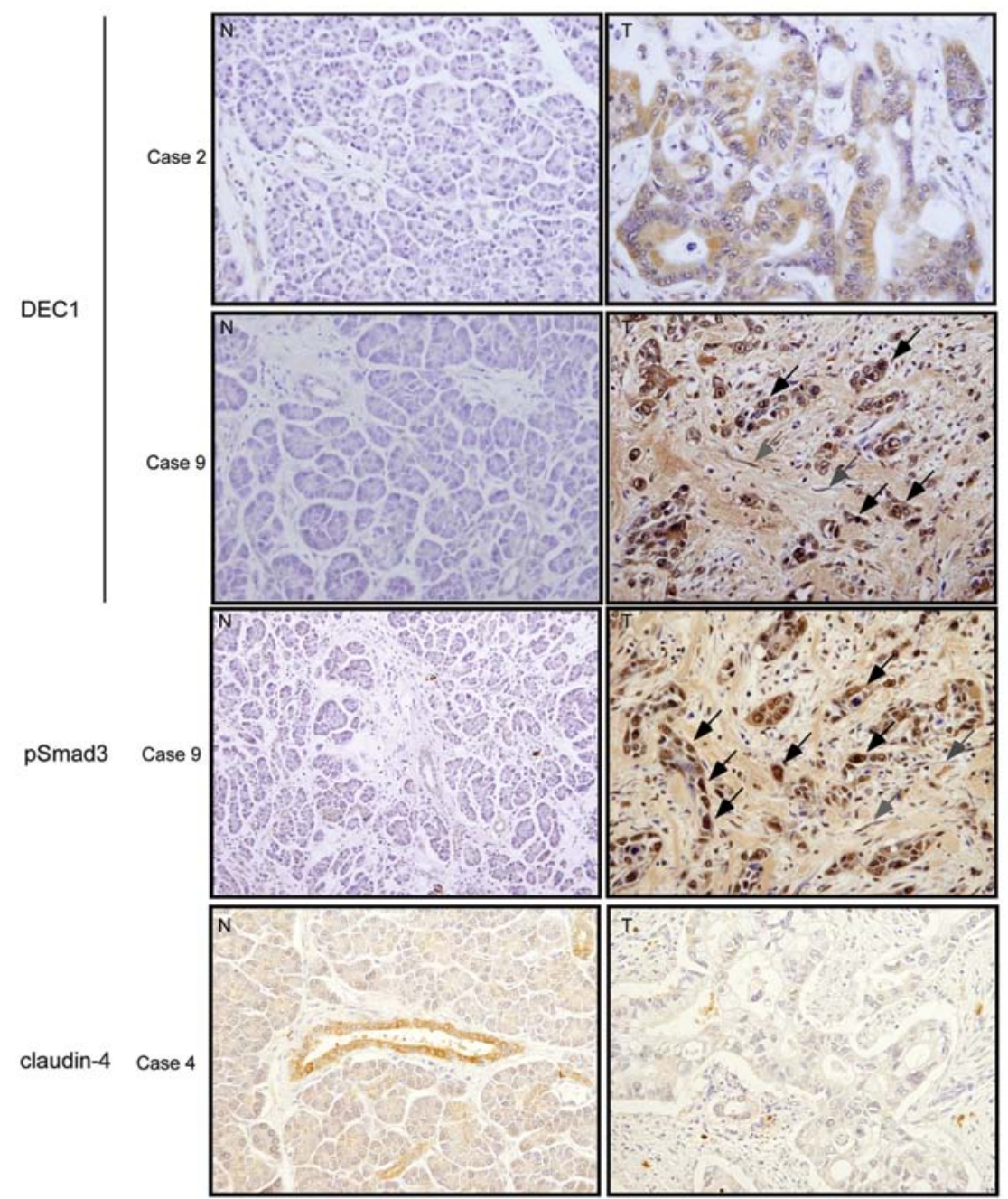

Figure 5. DEC1 and pSmad3 expression were increased in human pancreatic cancer tissues. Significant DEC1 immunoreactivity was detected in the pancreatic cancer tissues (case 2 involved moderately differentiated adenocarcinoma; right panel, labeled T), while it was weak in the non-cancerous pancreatic tissues (N, left panel). Strong DEC1 and pSmad3 immunoreactivities ware found in the spindle-shaped cancer cells (case 9 involved moderately differentiated adenocarcinoma; the black arrows show spindle-shaped cancer cells, whereas the gray arrows show fibroblasts; right panel, labeled T). Claudin-4 expression was strongly detected in the cytoplasm and the membrane of non-cancerous pancreatic ductal cells, while it was weak in the cancer tissues (case 4).

PaCa- 2 cells lacking the TGF- $\beta$ receptor, TGF- $\beta$ treatment had little effect on the expression of DEC1 and snail, and the Smad3 phosphorylation, and cell morphology. These findings suggest that DEC1 regulates pSmad3 by positive and negative feedback systems during EMT of pancreatic cancer.

Claudin-4 expression has been shown to decrease the invasiveness and metastatic potential of pancreatic cancer (36). Claudin and E-cadherin expression were found to be downregulated in breast, esophageal, and head and neck cancer tissue (37-39). The promoter regions of claudins and E-cadherin contain E-boxes $(15,40,41)$. We showed that DEC1 had effect on the expression and the amounts of claudin-4, claudin-7, and E-cadherin in the cell membrane, while DEC1 and claudin-4 were immunohistochemically detected in cancer tissues and non-cancerous ducts, respectively. Based on the above findings, $\mathrm{DEC} 1$ is considered to negatively regulate the expression of E-cadherin and claudins.

Our study is the first report to demonstrate marked pSmad3 immunoreactivity in pancreatic cancer cells compared with that in the adjacent non-cancerous pancreatic tissues. In particular, strong pSmad3 immunoreactivity was found in the nucleus of the spindle-shaped cancer cells, which were located at the cancer invasive front. A recent study reported that $\mathrm{Smad} 3$, but not Smad2, increased the expression of matrix metalloproteinase-9 in lung cancer cells and contributed to EMT through TGF- $\beta$ (42) which suggests that pSmad3 expression is closely involved in EMT of cancer cells.

In the present study, we demonstrated that DEC1 has inducible effects on EMT, which are mediated through the Smad3 phosphorylation, and plays an important role in EMT of pancreatic cancer; i.e., it alters the expression of EMT-related factors and affects the morphology, migration, and invasion of cancer cells.

\section{Acknowledgements}

This study was supported by Grants-in-Aid for Science from the Ministry of Education, Culture, Sports, Science, and Technology of Japan; a Grant for Hirosaki University Institutional Research; and the Fund for the Promotion of International Scientific Research. 


\section{References}

1. Thiery JP and Sleeman JP: Complex networks orchestrate epithelial-mesenchymal transitions. Nat Rev Mol Cell Biol 7: $131-142,2006$

2. Zavadil J and Böttinger EP: TGF-beta and epithelial-to-mesenchymal transitions. Oncogene 24: 5764-5774, 2005.

3. Miettinen PJ, Ebner R, Lopez AR and Derynck R: TGF-beta induced transdifferentiation of mammary epithelial cells to mesenchymal cells: involvement of type I receptors. J Cell Biol 127: 2021-2036, 1994

4. Moustakas A and Heldin CH: Signaling networks guiding epithelial-mesenchymal transitions during embryogenesis and cancer progression. Cancer Sci 98: 1512-1520, 2007.

5. Miyazawa K, Shinozaki M, Hara T, et al: Two major Smad pathways in TGF-beta superfamily signalling. Genes Cells 7 : $1191-1204,2002$

6. Giehl K, Seidel B, Gierschik P, et al: TGFbeta1 represses proliferation of pancreatic carcinoma cells which correlates with Smad4-independent inhibition of ERK activation. Oncogene 19: 4531-4541, 2000.

7. Hahn SA, Schutte M, Hoque AT, et al: DPC4, a candidate tumor suppressor gene at human chromosome 18q21.1. Science 271 350-353, 1996

8. Bartsch D, Hahn SA, Danichevski KD, et al: Mutations of the DPC4/Smad4 gene in neuroendocrine pancreatic tumors. Oncogene 18: 2367-2371, 1999.

9. Massagué J: How cells read TGF-beta signals. Nat Rev Mol Cell Biol 1: 169-178, 2000.

10. Zawel L, Dai JL, Buckhaults P, et al: Human Smad3 and Smad4 are sequence-specific transcription activators. Mol Cell 1: 611-617, 1998

11. Ohashi S, Natsuizaka M, Naganuma S, et al: A NOTCH3mediated squamous cell differentiation program limits expansion of EMT-competent cells that express the ZEB transcription factors. Cancer Res 71: 6836-6847, 2011.

12. Dave N, Guaita-Esteruelas S, Gutarra S, et al: Functional cooperation between Snaill and twist in the regulation of ZEB1 expression during epithelial to mesenchymal transition. J Biol Chem 286: 12024-12032, 2011.

13. Gregory PA, Bracken CP, Smith E, et al: An autocrine TGF-beta/ ZEB/miR-200 signaling network regulates establishment and maintenance of epithelial-mesenchymal transition. Mol Biol Cell 22: 1686-1698, 2011

14. Hong J, Zhou J, Fu J, et al: Phosphorylation of serine 68 of Twist1 by MAPKs stabilizes Twist 1 protein and promotes breast cancer cell invasiveness. Cancer Res 71: 3980-3990, 2011.

15. Ikenouchi J, Matsuda M, Furuse M and Tsukita S: Regulation of tight junctions during the epithelium-mesenchyme transition: direct repression of the gene expression of claudins/occludin by Snail. J Cell Sci 116: 1959-1967, 2003.

16. Ohkubo $\mathrm{T}$ and Ozawa M: The transcription factor Snail downregulates the tight junction components independently of E-cadherin downregulation. J Cell Sci 117: 1675-1685, 2004.

17. Zavadil J, Cermak L, Soto-Nieves N, et al: Integration of TGF-beta/Smad and Jagged1/Notch signalling in epithelial-tomesenchymal transition. EMBO J 23: 1155-1165, 2004.

18. Wu Y, Sato F, Bhawal UK, et al: Basic helix-loop-helix transcription factors DEC1 and DEC2 regulate the paclitaxelinduced apoptotic pathway of MCF-7 human breast cancer cells. Int J Mol Med 27: 491-495, 2011.

19. Liu Y, Sato F, Kawamoto T, et al: Anti-apoptotic effect of the basic helix-loop-helix (bHLH) transcription factor DEC2 in human breast cancer cells. Genes Cells 15: 315-325, 2010.

20. Bhawal UK, Sato F, Arakawa Y, et al: Basic helix-loop-helix transcription factor DEC1 negatively regulates cyclin D1. J Pathol 224: 420-429, 2011

21. Li Y, Xie M, Yang J, et al: The expression of antiapoptotic protein survivin is transcriptionally upregulated by DEC1 primarily through multiple spl binding sites in the proximal promoter. Oncogene 25: 3296-3306, 2006.
22. Turley H, Wykoff CC, Troup S, et al: The hypoxia-regulated transcription factor DEC1 (Stra13, SHARP-2) and its expression in human tissues and tumours. J Pathol 203: 808-813, 2004.

23. Chakrabarti J, Turley $\mathrm{H}$, Campo L, et al: The transcription factor DEC1 (stra13, SHARP2) is associated with the hypoxic response and high tumour grade in human breast cancers. Br J Cancer 91: 954-958, 2004.

24. Giatromanolaki A, Koukourakis MI, Sivridis E, et al: DEC1 (STRA13) protein expression relates to hypoxia- inducible factor 1-alpha and carbonic anhydrase- 9 overexpression in non-small cell lung cancer. J Pathol 200: 222-228, 2003.

25. Kondo J, Sato F, Kusumi T, et al: Claudin-1 expression is induced by tumor necrosis factor- $\alpha$ in human pancreatic cancer cells. Int J Mol Med 22: 645-649, 2008

26. Suzuki T, Sato F, Kondo J, et al: Period is involved in the proliferation of human pancreatic MIA-PaCa2 cancer cells by TNF-alpha. Biomed Res 29: 99-103, 2008.

27. Sato F, Wu Y, Bhawal UK, Liu Y, et al: PERIOD1 (PER1) has anti-apoptotic effects, and PER3 has pro-apoptotic effects during cisplatin (CDDP) treatment in human gingival cancer CA9-22 cells. Eur J Cancer 47: 1747-1758, 2011.

28. Li Y, Zhang H, Xie M, et al: Abundant expression of Dec1/ stra13/sharp2 in colon carcinoma: its antagonizing role in serum deprivation-induced apoptosis and selective inhibition of procaspase activation. Biochem J 367: 413-422, 2002.

29. Wang W, Reiser-Erkan C, Michalski CW, et al: Hypoxia inducible BHLHB2 is a novel and independent prognostic marker in pancreatic ductal adenocarcinoma. Biochem Biophys Res Commun 401: 422-428, 2010.

30. Kon N, Hirota T, Kawamoto T, et al: Activation of TGF-beta/ activin signalling resets the circadian clock through rapid induction of Dec1 transcripts. Nat Cell Biol 10: 1463-1469, 2008.

31. Nicolás FJ and Hill CS: Attenuation of the TGF-beta-Smad signaling pathway in pancreatic tumor cells confers resistance to TGF-beta-induced growth arrest. Oncogene 22: 3698-3711, 2003.

32. Sato F, Kawamoto T, Fujimoto K, et al: Functional analysis of the basic helix-loop-helix transcription factor DEC1 in circadian regulation. Interaction with BMAL1. Eur J Biochem 271: 4409-4419, 2004.

33. Kawamoto T, Noshiro M, Sato F, et al: A novel autofeedback loop of Dec1 transcription involved in circadian rhythm regulation. Biochem Biophys Res Commun 313: 117-124, 2004.

34. Bloom BB, Humphries DE, Kuang PP, et al: Structure and expression of the promoter for the R4/ALK5 human type I transforming growth factor-beta receptor: regulation by TGF-beta. Biochim Biophys Acta 1312: 243-248, 1996.

35. Mulder KM: Role of ras and Mapks in TGF-beta signaling. Cytokine Growth Factor Rev 11: 23-35, 2000.

36. Michl P, Barth C, Buchholz M, et al: Claudin-4 expression decreases invasiveness and metastatic potential of pancreatic cancer. Cancer Res 63: 6265-6271, 2003.

37. Turksen $\mathrm{K}$ and Troy TC: Junctions gone bad: Claudins and loss of the barrier in cancer. Biochim Biophys Acta 1816: 73-79, 2011.

38. Berx G and Van Roy F: The E-cadherin/catenin complex: an important gatekeeper in breast cancer tumorigenesis and malignant progression. Breast Cancer Res 3: 289-293, 2001.

39. Wells A, Yates C and Shepard CR: E-cadherin as an indicator of mesenchymal to epithelial reverting transitions during the metastatic seeding of disseminated carcinomas. Clin Exp Metastasis 25: 621-628, 2008

40. Martínez-Estrada OM, Cullerés A, Soriano FX, et al: The transcription factors Slug and Snail act as repressors of Claudin-1 expression in epithelial cells. Biochem J 394: 449-457, 2006.

41. Batlle E, Sancho E, Francí C, et al: The transcription factor snail is a repressor of E-cadherin gene expression in epithelial tumour cells. Nat Cell Biol 2: 84-89, 2002.

42. Reka AK, Kurapati H, Narala VR, et al: Peroxisome proliferatoractivated receptor-gamma activation inhibits tumor metastasis by antagonizing Smad3-mediated epithelial-mesenchymal transition. Mol Cancer Ther 9: 3221-3232, 2010. 